JFFI. 2019; 6(2) 347-352

www.jurnal.farmasi.umi.ac.id/index.php/fitofarmakaindonesia

\title{
EFEK PERBEDAAN PELARUT TERHADAP UJI TOKSISITAS EKSTRAK PINEUNG NYEN TEUSALE
}

\author{
Hilka Yuliani*, Maya Indra Rasyid \\ Prodi Teknologi Hasil Pertanian, Fakultas Pertanian, Universitas Teuku Umar \\ *hilka.yuliani@utu.ac.id
}

Submission Date: 07-12-2018; $\quad$ Review Completed: 11-05-2019; $\quad$ Accepted Date: 28-05-2019

\begin{abstract}
Smoked young areca nut seed or pineung nyen teusalee is a material commonly used by the Acehnese as medicine, especially diabetes medicine. This study aims to determine the phytochemical content and toxicity level of pineung nyen teusalee extracted using ethanol and aquadest. The concentration of pineung nyen teusalee extract solution used as the toxicity test concentration was $0 \mathrm{mg} / \mathrm{L}, 50 \mathrm{mg} / \mathrm{L}, 100 \mathrm{mg} / \mathrm{L}, 500 \mathrm{mg} / \mathrm{L}$, and $1000 \mathrm{mg} / \mathrm{L}$. Qualitative methods were used in testing phytochemical compounds while the toxicity level of $L C_{50}$ using probit analysis using SPSS version 16.0 software. From the results of phytochemical analysis tests (flavonoids, tannins, and saponins) positive results were obtained for ethanol extract and aquadest extract for all phytochemical test parameters. Probit analysis showed that the concentration of ethanol extract of pineung nyen teusalee had a toxic effect on $50 \%$ of the population of Artemia salina Leach larvae with $L C_{50}$ values of $115.71 \mathrm{mg} / \mathrm{L}$. While the concentration of aquadest extract of pineung nyen teusalee gave an $L C_{50}$ value of $338.40 \mathrm{mg} / \mathrm{L}$.
\end{abstract}

Keywords: Areca nut; Phytochemical; Toxicity test

\section{PENDAHULUAN}

Biji Pinang (Areca catechu L.) merupakan salah satu tanaman obat di Indonesia yang memiliki banyak manfaat, salah satu manfaatnya yaitu berkhasiat sebagai antidiabetik dan antihiperglikemik. Masyarakat Aceh menggunakan biji pinang muda yang diasapi yang disebut dengan pineung nyen teusale secara empiris untuk mengobati penyakit diabetes. Biji pinang muda paling banyak digunakan karena memiliki bahan aktif yang paling tinggi (Haditomo, 2010) diantaranya alkaloid (arekolin, arrekoidin, gurasin, guvalin) sekitar 0,3 - 0,6\%, flavonoid, tanin sekitar 15\% dan saponin (Novarianto, 2012; Sa'roni dan Anjirni, 2005). Senyawa arekolin yang terkandung dalam pinang dilaporkan memiliki aktivitas antihiperglikemik (Voigt et al. 2013; Jensen et al. 2014). Namun, arekolin diketahui dapat bersifat memabukkan bagi penggunanya (Grieve, 1995).

Ekstraksi merupakan suatu proses pemisahan bahan padat maupun cair dengan bantuan pelarut. Pelarut yang digunakan harus dapat mengekstrak substansi yang diinginkan tanpa melarutkan material lainnya. Ekstraksi menggunakan pelarut didasarkan pada kelarutannya (Ansel, 1989).Jenis pelarut dalam ekstraksi, dapat mempengaruhi perolehan kadar zat aktif dari tumbuhan. Maka dari itu, pemakaian pelarut yang terbaik akan semakin mempertinggi optimalisasi dalam pengekstraksi sampel. Pelarut metanol adalah salah satu pelarut yang dapat mengekstraksi golongan semua flavonoid dan juga salah satu pelarut yang lebih polar digunakan untuk mengekstraksi glikosida flavonoid (Miryanti, 2011). Penelitian ini menggunakan pelarut etanol dan aquadest dikarenakan kedua pelarut tersebut memiliki sifat semi polar dan polar. Sarastani et al. (2002), ekstraksi menggunakan pelarut dengan polaritas berbeda dapat menghasilkan ekstrak dengan polaritas yang berbeda pula sesuai dengan sifat kepolaran masing-masing ekstrak.

Perbedaan penggunaan jenis pelarut menyebabkan senyawa yang terlarut akan berbeda, yang dapat berakibat terhadap perbedaan tingkat toksisitas. Perlu dilakukan uji toksisitas biji pinang muda dengan menggunakan jenis-jenis pelarut yang berbeda untuk mengetahui batas $\mathrm{LC}_{50}$ dari biji pinang muda pada larva udang Artemia salina Leach. Penelitian mengenai toksisitas pineung nyen teusale dengan pelarut yang berbeda belum banyak dilakukan, sehingga penelitian ini perlu dilakukan.

\section{METODE PENELITIAN}

\section{A. Alat dan Bahan}

Penelitian ini dilakukan di Laboratorium Pertanian dan Laboratorium Dasar Universitas Teuku Umar. Bahan yang digunakan dalam penelitian ini adalah biji pinang muda asap/pineung nyen teusalee 
yang diambil di kabupaten Bireun Aceh, etanol, aquadest, larva Artemia salina Leach, ragi sebagai pakan larva udang, dan garam ikan.

Alat-alat yang digunakan dalam penelitian ini adalah gelas ukur, pisau, neraca analitik, pipet, batang pengaduk kaca, lup, vial atau botol kaca, kain flannel hitam, kain saring, penangas air, akuarium, pengatur udara dan lampu.

Metode yang digunakan yaitu uji BSLT yang bertujuan untuk menentukan $\mathrm{LC}_{50}$ terhadap pelarut yang bersifat toksik dan non toksik. Penelitian ini memiliki beberapa tahapan pembuatan ekstrak senyawa aktif pineung nyen teusalee dengan pelarut berbeda, pengujian fitokimia pada ektrak, analisa probit pada hewan uji artemia.

\section{B. Prosedur Penelitian}

1. Persiapan sampel (pembuatan ekstrak Pineung Nyen Teusalee) (Meiyanto et al, 2008 termodifikasi)

Biji Pineung Nyen Teusalee sebanyak $1 \mathrm{~kg}$ dikumpulkan dari Bireun. Biji Pineung Nyen Teusalee dicuci bersih, dipotong-potong dan dikeringkan dalam oven dengan suhu $70^{\circ} \mathrm{C}$. Simplisia yang telah kering diserbuk, diekstraksi dengan metode maserasi, dengan cara merendam Pineung Nyen Teusalee kering dalam pelarut alkohol $70 \%$ selama 24 jam, lalu disaring dengan kain saring dan direndam kembali dalam alkohol $70 \%$ sampai tersaring atau terekstraksi sempurna yang ditandai dengan warna alkohol menjadi bening kembali.

Setelah itu, pelarut alkohol yang masih tersisa diuapkan pada penangas air atau water bath serta diangin-anginkan sehingga didapatkan ekstrak yang kental dengan konsentrasi $100 \%$. Kemudian ekstrak Pineung Nyen Teusalee yang diperoleh juga ditimbang dan didapatkan berat ekstrak Pineung Nyen Teusalee murni. Untuk mendapatkan konsentrasi ekstrak yang efektif membunuh larva Artemia salina Leach, maka dilakukan trial atau orientasi dengan uji coba dengan menggunakan konsentrasi desimal, yaitu $1 \% ; 0,5 \% ; 0,25 \%$ dan $0,1 \%$. Setelah dilakukan trial atau uji orientasi, didapatkan bahwa konsentrasi terkecil yang dapat menyebabkan kematian pada hampir semua larva adalah $0,1 \%$, maka konsentrasi yang ditetapkan untuk perlakuan dan replikasinya adalah $0,01 \% ; 0,02 \% ; 0,05 \%$ dan $0,1 \%$.

2. Uji Fitokimia

Uji Flavonoid (Harborne, 1996)

Ekstrak ditimbang sebanyak $50 \mathrm{mg}$ dan ditambahkan air panas sebanyak $100 \mathrm{~mL}$ kemudian didihkan selama 5 menit dan disaring. 0,05 mg serbuk Magnesium ditambahkan ke dalam filtrat sebanyak 5 $\mathrm{mL}$ dan $1 \mathrm{~mL} \mathrm{HCl}$ pekat, kemudian dikocok dengan kuat. Warna merah magenta yang terbentuk menunjukkan adanya senyawa flavonoid.
Uji Tanin (Harborne, 1996)

Ekstrak ditimbang sebanyak $50 \mathrm{mg}$ dilarutkan dalam $2 \mathrm{~mL}$ air kemudian ditambahkan 2 tetes larutan $\mathrm{FeCl} 31 \%$. Adanya tannin ditunjukkkan dengan terbentuknya warna biru kehitaman dan hijau kehitaman.

Uji Saponin (Harborne, 1996)

Ekstrak ditimbang sebanyak $50 \quad \mathrm{mg}$ kemudian ditambahkan $10 \mathrm{~mL}$ air dan dikocok selama 1 menit. Setelah itu ditambahkan 2 tetes $\mathrm{HCl} 1 \mathrm{~N}$. Adanya saponin ditunjukkan dengan terbentuknya busa yang tetap stabil selama 7 menit.

Pemilihan telur Artemia salina Leach

Pemilihan telur udang dilakukan dengan merendam telur dalam aquadest selama satu jam. Telur yang baik akan mengendap sedangkan telur yang kurang baik akan mengapung.

Penyiapan larva Artemia Salina Leach

Penyiapan larva udang dilakukan dengan menetaskan telur udang 48 jam sebelum dilakukan uji. Penetasan dilakukan dengan merendam telur tersebut dalam air laut secukupnya dengan menerangi bagian wadah yang tidak ditempati telur udang dengan sinar lampu.

3. Pembagian kelompok perlakuan

Pada penelitian ini larva udang dibagi dalam lima kelompok perlakuan secara acak, yaitu:

a) Kelompok Kontrol adalah 10 larva udang yang diberi ekstrak Pineung Nyen Teusalee dengan konsentrasi $0 \mathrm{mg} / \mathrm{L}$ dalam media.

b) Kelompok P1 adalah 10 larva udang yang diberi ekstrak Pineung Nyen Teusalee dengan konsentrasi $50 \mathrm{mg} / \mathrm{L}$ dalam media.

c) Kelompok P2 adalah 10 larva udang yang diberi ekstrak Pineung Nyen Teusalee dengan konsentrasi $100 \mathrm{mg} / \mathrm{L}$ dalam media.

d) Kelompok P3 adalah 10 larva udang yang diberi ekstrak Pineung Nyen Teusalee dengan konsentrasi $500 \mathrm{mg} / \mathrm{L}$ dalam media.

e) Kelompok P4 adalah 10 larva udang yang diberi ekstrak Pineung Nyen Teusalee dengan konsentrasi $1000 \mathrm{mg} / \mathrm{L}$ dalam media.

4. Penentuan $\mathrm{LC}_{50}$

10 ekor udang Artemia salina dimasukkan kedalam larutan uji dengan konsentrasi 1000, 500, 250, 100, $50 \mathrm{mg} / \mathrm{L}$ dan pada kontrol. Setiap larutan uji dilakukan 5 kali pengulangan dan dibandingkan dengan kontrol. Pengamatan terhadap udang Artemia salina Leach dilakukan selama 24 jam. Prosentase kematian udang Artemia salina Leach dihitung dengan persamaan berikut:

$\%$ Mortalitas $=\frac{\text { Jumlah larva yang mati }}{\text { Jumlah larva uji }} \times 100 \%$

Rumus Abbot's digunakan apabila pada kontrol ada udang yang mati: 
$\%$ Mortalitas=

$\%$ kematian pada uji- $\%$ kematian pada kontrol

100-\% Kematian pada kontrol x $100 \%$

5. Data yang dikumpulkan

Data yang dikumpulkan adalah data primer yang didapatkan dari jumlah larva udang yang mati 24 jam setelah perlakuan pada tiap-tiap konsentrasi ekstrak biji pineung nyen teusalee.

6. Analisis data

Data hasil penelitian akan diolah dan disajikan dalam bentuk tabel dan grafik. Penentuan Nilai LC $_{50}$ Penentuan nilai LC $_{50}$ menggunakan metode anilasa probit SPSS 16.0.

\section{HASIL DAN PEMBAHASAN Proses Ekstraksi}

Pembuatan ekstrak biji pinang muda dilakukan melalui proses ekstraksi dengan metode maserasi. Proses ekstraksi merupakan suatu cara untuk memisahkan campuran beberapa zat menjadi komponen-komponen yang terpisah yang meliputi pembuatan serbuk, pembahasan, penyaringan, dan pemekatan (Ansel, 1989; Williams, 1981). Maserasi yaitu proses ekstraksi dimana sampel yang sudah halus memungkinkan untuk direndam dalam pelarut sampai meresap dan melunakkan susunan sel, sehingga yang mudah larut akan melarut dan metode ini baik digunakan untuk komponen yang tidak tahan panas (Ansel, 1989). Pelarut yang digunakan yaitu etanol dan aquadest yang memiliki sifat polar. Pelarut lebih cenderung melarutkan senyawa aktif yang mempunyai golongan sama, sedangkan untuk semi polar dapat melarutkan sebagian atau seluruh senyawa aktif dari golongan polar dan nonpolar (Keenan et al, 1990).

Senyawa yang terkandung dalam ekstrak etanol biji pinang adalah senyawa-senyawa yang larut dalam pelarut polar (Rairisti, 2014). Hal ini sesuai dengan penelitian yang dilakukan oleh Sa'roni dan Adjirni (2005), yang menyatakan bahwa ekstraksi biji pinang dengan pelarut etanol mengandung senyawa alkaloid, saponin, tanin, dan flavonoid.

Hasil ekstraksi pineung nyen teusalee dengan berat simplisia 50 gram dengan menggunakan 2 pelarut yaitu etanol dan aquadest ditampilkan pada tabel 1 .

Tabel 1. Hasil Ekstraksi Pineung Nyen Teusalee

\begin{tabular}{ccccc}
\hline Ekstrak & Berat ekstrak $(\mathbf{g})$ & Rendemen $(\boldsymbol{\%})$ & Bentuk & Warna \\
\hline Etanol & 32,7 & 65,6 & Pasta & Coklat kehitaman \\
Aquadest & 23,8 & 47,6 & Pasta & Coklat kehitaman \\
\hline
\end{tabular}

Ekstrak pineung nyen teusalee memiliki rendemen ekstrak etanol sebesar $65,6 \%$ dan aquadest sebesar $47,6 \%$. Hal ini diduga pineung nyen teusalee memiliki senyawa bioaktif yang bersifat polar. Menurut Leksono et al. (2018), setiap pelarut memiliki karakter berbeda dalam mengambil senyawa bioaktif suatu sampel yang berbeda kepolarannya.
Pelarut etanol dan aquadest yang digunakan dalam ekstraksi untuk mendapatkan senyawa berdasarkan tingkat kepolarannya.

\section{Uji Fitokimia}

Adapun hasil uji fitokimia berbagai fraksi ditunjukkan pada Tabel 2.

Tabel 2. Hasil Uji Fitokimia Berbagai Fraksi

\begin{tabular}{ccc}
\hline \multirow{2}{*}{ Jenis Senyawa } & \multicolumn{2}{c}{ Jenis Ekstrak } \\
& Fraksi Aquadest & Fraksi Etanol \\
\hline Flavonoid & + & + \\
Tanin & + & + \\
Saponin & + & + \\
\hline
\end{tabular}

\section{Uji Flavonoid}

Keterangan: (+) terdapat senyawa bioaktif

Uji flavonoid dilakukan dengan menambahakan serbuk $\mathrm{Mg}$ dan $\mathrm{HCl}$ pekat sehingga menghasilkan warna merah, kuning, atau jingga akibat reduksi dengan magnesium dan $\mathrm{HCl}$ pekat. Dari hasil pengujian diperoleh bahwa ekstrak etanol dan aquadest positif mengandung flavonoid.

\section{Uji Tanin}

Hasil uji tanin dari sampel pineung nyen teusalee hasil eksktraksi etanol dan aquadest dengan pereaksi $\mathrm{FeCl}_{3} \quad 0,1 \%$ menunjukkan uji positif yaitu warna larutan menjadi kuning kehijauan. Hal ini terjadi karena adanya reaksi reduksi.

\section{Uji Saponin}

Hasil uji saponin dari sampel pineung nyen teusalee hasil ekstraksi etanol dan aquadest menunjukkan hasil positif yang ditandai dengan pereaksi aquadest menunjukkan uji positif yaitu terbentuknya busa yang konsisten selama 7 menit. Menurut Prihatna (2001), saponin memiliki 
karakteristik berupa buih, sehingga ketika direaksikan dengan air dan dikocok maka akan terbentuk buih yang dapat bertahan lama. Saponin mudah larut dalam air dan tidak larut dalam eter, memiliki rasa pahit menusuk.

\section{Uji Aktifitas Toksisitas dengan Menggunakan} BSLT

Lethal Concentration $\left(\mathrm{LC}_{50}\right)$ adalah konsentrasi yang menyebabkan kematian 50\% dari organisme uji pada suatu waktu pengamatan tertentu (Astuti, 2004; Rossiana, 2006). Berdasarkan hasil di atas, terdapat perbedaan tingkat toksisitas dari ekstrak pineung nyen, hal ini juga karena perbedaan jenis pelarut yang digunakan, sehingga menyebabkan senyawa yang terlarut akan berbeda yang dapat berakibat terhadap perbedaan tingkat toksisitas pada larva udang Artemia salina.

Tabel 3. Hasil uji BSLT dari setiap fraksi pada pineung nyen teusalee

\begin{tabular}{cccccc}
\hline Sampel & $\begin{array}{c}\text { Konsentrasi } \\
\text { mg/L }\end{array}$ & $\begin{array}{c}\text { Akumulasi } \\
\text { hidup }\end{array}$ & $\begin{array}{c}\text { Akumulasi } \\
\text { mati }\end{array}$ & $\begin{array}{c}\text { Mortalitas } \\
(\%)\end{array}$ & LC50 \\
\hline Ekstrak & 50 & 7,67 & 2,33 & 23,3 & \\
Etanol & 100 & 7,33 & 2,67 & 26,7 & 115,71 \\
& 500 & 0 & 10 & 100 & $\mathrm{mg} / \mathrm{L}$ \\
& 1000 & 0 & 10 & 100 & \\
Ekstrak & 50 & 8 & 2 & 20 & 338,40 \\
Aquadest & 100 & 7 & 3 & 30 & $\mathrm{mg} / \mathrm{L}$ \\
& 500 & 5,33 & 4,67 & 46,7 & 76,7 \\
\hline
\end{tabular}

Tingkat kematian larva tidak hanya dipengaruhi oleh komponen kimia yang terkandung di dalamnya tetapi erat hubungannya dengan konsentrasi terhadap larva Artemia salina. Konsentrasi yang digunakan dalam penelitian ini adalah $50 \mathrm{mg} / \mathrm{L}, 100$ $\mathrm{mg} / \mathrm{L}, 500 \mathrm{mg} / \mathrm{L}$ dan $1000 \mathrm{mg} / \mathrm{L}$ terhadap ektrak etanol dan ekstrak aquadest. Pada konsentrasi terendah sampai tertinggi $(50-1000 \mathrm{mg} / \mathrm{L})$ ekstrak etanol didapatkan persentase kematian larva Artemia salina sebesar23,3\%, 26,7\%, $100 \%$ dan $100 \%$. Sedangkan untuk ekstrak aquadest diperoleh persentase kematian larva Artemia salina pada konsentrasi terendah sampai tertinggi (50 - 1000 $\mathrm{mg} / \mathrm{L})$ yaitu 20\%, 30\%, 46,7\% dan 76,7\%. Ekstrak etanol merupakan ekstrak yang paling aktif karena pada konsentrasi $500 \mathrm{mg} / \mathrm{L}$ mampu membunuh $100 \%$ larva udang dalam waktu 24 jam. Analisis probit menunjukkan bahwa konsentrasi ekstrak etanol pineung nyen teusalee memberikan efek toksik terhadap 50\% populasi larva Artemia salina dengan nilai LC $_{50} 115,71 \mathrm{mg} / \mathrm{L}$. Sedangkan konsentrasi ekstrak aquadest pineung nyen teusalee memberikan nilai $\mathrm{LC}_{50} 338,40 \mathrm{mg} / \mathrm{L}$. Nilai ini menunjukkan bahwa pada konsentrasi dimana ekstrak tersebut dapat membunuh $50 \%$ hewan uji. Berdasarkan nilai $\mathrm{LC}_{50}$ ekstrak etanol dan aquadest pineung nyen teusalee bersifat toksik dikarenakan nilai $\mathrm{LC}_{50}$ berada lebih rendah dari $1000 \mathrm{mg} / \mathrm{L}$. Menurut Meyer et al (1982), tingkat toksisitas suatu ekstrak adalah sebagai berikut: $\mathrm{LC}_{50} \leq 30 \mathrm{mg} / \mathrm{L}=$ sangat toksik; $\mathrm{LC}_{50} \leq 1.000 \mathrm{mg} / \mathrm{L}=$ toksik; $\mathrm{LC}_{50}>1.000 \mathrm{mg} / \mathrm{L}=$ tidak toksik.Menurut Ningdah et al. (2015) tinggi rendahnya kematian larva berbanding terbalik dengan nilai $\mathrm{LC}_{50}$. Ketika nilai
$\mathrm{LC}_{50}$ besar maka tingkat kematian larva akan semakin rendah begitu juga sebaliknya.

Berdasarkan konsentrasi larutan uji yang digunakan, diperoleh bahwa konsentrasi dan jenis pelarut yang digunakan mempengaruhi tingkat toksisitas suatu bahan. Konsentrasi dan jenis pelarut yang bervariasi pada setiap botol uji memiliki jumlah kematian A. Salina yang berbeda. Hasil uji BSLT konsentrasi $1000 \mathrm{mg} / \mathrm{L}$ etanol menyebabkan rata-rata kematian larva tertinggi, sedangkan pada aquadest menunjukkan kematian terendah. Kelompok kontrol tanpa penambahan ekstrak tidak ditemukan adanya kematian pada larva. Hal tersebut menujukkan bahwa setiap konsentrasi memiliki pengaruh yang berbeda pada kematian larva $A$. Salina. Semakin tinggi konsentrasi ekstrak maka semakin tinggi pula jumlah kematian larva. Hal ini sesuai dengan Harbone (1994) yang menyebutkan bahwa semakin tinggi konsentrasi ekstrak maka sifat toksiknya akan semakin tinggi.

Perbedaan pelarut dalam ekstraksi dapat mempengaruhi kandungan total senyawa bioaktif (Santoso et al, 2012). Hal ini disebabkan karena perbedaan polaritas dari pelarut (Megha et al., 2014). Proses ekstraksi dipengaruhi oleh beberapa faktor, diantaranya jenis pelarut, perbandingan pelarut dengan bahan ekstraksi, suhu, tekanan dan waktu ekstraksi serta komponen bioaktif tumbuhan. Jika kondisi suhu dan temperatur sama, maka jenis pelarut dan komponen senyawa kimia yang terdapat pada tanaman menjadi faktor yang menentukan keberhasilan proses ekstraksi (Lopez, 2011). Adanya sistem perendaman, maka pelarut akan menembus dinding sel dan masuk ke dalam sel yang mengandung 
zat aktif sehingga akan larut dalam pelarut (Khoiriyah, 2014).

Kedua jenis ektrak berbentuk pasta dengan aroma yang khas. Karakteristik warna filtrat relatif sama antara ekstrak etanol dan aquadest yaitu coklat terang, sedangkan ekstrak kasar kadar dari kedua jenis pelarut menunjukkan warna yang relatif sama yaitu coklat pekat. Ekstrak terbanyak diperoleh pada ekstrak aquadest. Hal ini berarti bahwa sampel pineung nyen teusalee mengandung senyawa polar tertinggi. Hal ini berarti bahwa senyawa-senyawa aktif pada pineung nyen teusalee relatif larut dalam pelarut polar.

\section{KESIMPULAN}

Adapun kesimpulan yang dapat diperoleh dari penelitian ini adalah:

1. Pelarut untuk ekstraksi berpengaruh terhadap hasil ekstraksi.

2. Variasi konsentrasi dan jenis pelarut yang digunakan dalam ekstraksi mempengaruhi tingkat toksisitas pineung nyen teusalee.

3. Semakin tinggi konsentrasi maka semakin tinggi sifat toksisitasnya.

\section{UCAPAN TERIMA KASIH}

Terima kasih kami sampaikan kepada Kementrian Riset, teknologi dan Pendidikan Tinggi atas bantuan dana penilitian, Fakultas Pertanian dan Laboratorium Dasar Universitas Teuku Umar atas segala fasilitas yang diberikan selama penelitian ini, serta semua pihak yang telah membantu sehingga penelitian ini dapat berjalan lancar.

\section{DAFTAR PUSTAKA}

Ansel, H.C. (1989). Pengantar Bentuk Sediaan Farmasi, Penerjemah: Farida Ibrahim. 2008. UI Press. Jakarta.

Grieve, M. (1995). A Modern Herbal (Areca Nut). [online].

Tersedia http://www.botanical.com/botanical/mgmh/ a/arecaorg.html.

Haditomo, I. (2010) 'Efek Larvasida Ekstrak Biji Pinang (Areca catechu) terhadap Aedes aegypti L'. Fakultas Kedokteran Universitas Sebelas Maret. Surakarta.

Harborne, J.B. (1987) Metode Fitokimia, Penuntun Cara Modern Menganalisis Tumbuhan, Penerjemah: K. Padmawinata dan $I$. Soediro. Terbitan ke-2. ITB. Bandung.

Khoiriyah, S., Hanapi, S., dan Fasya, A.G. (2014) 'Uji Fitokimia dan Aktivitas Antibakteri Fraksi Etil Asetat, Kloroform, dan Petroleum Eter Ekstrak Metanol Alga Coklat Sargassum vulgare dari Pantai Kapong Pamekasan
Madura', Alchemy: Journal of Chemisty. 3(2), pp. $133-144$.

Lopez, A. Rico, M, Rivero, A,., dan de Tangil, M.S. (2011) 'The Effects of Solvent on The Phenolic Contents and Antioxidant Activity of Stypocaulon scoparium algae Extracts', Food Chemistry. 125(3), pp. $1104-1109$.

Megha, N.M dan Sabale, A.B. (2014) 'Antimicrobial, Antioxidant and Haemolityc Potential of Brown Macroalga Sargosum', World Journal of Pharmacy and Pharmaceutical Sciences. 3(8), pp. $2091-2104$.

Miryanti, A. (2011) Ekstraksi Antioksidan dari Kulit Buah Manggis (Garcinia mangostana L.). Bandung.

Ningdyah, A.W, Andi, H.A, dan Afghani Jayuska. (2015) 'Uji Toksisitas dengan Metode BSLT (Brine Shrimp Lethality Test) terhadap Hasil Fraksinasi Ekstrak Kulit Buah Tampoi (Baccaurea macrocarpa)', JKK. 4(1), pp. 75 - 83. ISSN: 2303 -1077.

Novarianto, H. (2012) Prospek Pengembangan Tanaman Pinang. Balai Penelitian Tanaman Palma. Manado.

Prihatna, K. (2001) Saponin untuk Pembasmi Hama Udang. Penelitian perkebunan Gambung. Bandung.

Rairisti, A. (2014) 'Uji Aktivitas Ekstrak Etanol Biji Pinang (Areca catechu L.) terhadap Penyembuhan Luka Sayat pada Tikus Putih (Rattus norvegicus) Jantan Galur wistar', [Skripsi]. Program Studi Pendidikan Dokter. Fakultas Kedokteran. Universitas Tanjungpura.

Sa'roni dan Adjirni. (2005) 'Spesifikasi Simplisia dan Ekstrak Etanol Biji Pinang (Areca catechu) Asal Tawamangu serta Toksisitas Akut dan Khasiat Hemostatiknya pada Hewan Coba', [online], tersedia http://ejournal.litbang.depkes.go.id/index.ph p/MPK/article/download/1136/480.

Santoso, J., Anwariyah, S., Rumiantin, R. O., Putri, A.P., Ukhty, N., dan Yoshie-stark, Y. (2012) 'Phenol Content, Antioxidant Activity and Fibers Profile of Four Tropical Seagrasses from Indonesia', Journal of Coastal Development, 15(2), pp. 189 - 196.

Sarastani, D. Soekarto, S.T, Muchtadi, T.R, Fardiaz, D., dan Apriyantono, A. (2002) 'Aktivitas Antioksidan ekstrak dan fraksi Ekstrak Biji Atung', Jurnal. Teknol. Ind. Pang, 13(2), pp. $149-156$.

Sharon, N. Anam, S. Yuliet. (2013) 'Formulasi Krim Antioksidan Ekstrak Etanol Bawang Hutan (Eleutherine palmifolia L. Merr)', Jurnal of 
Natural Science, 2(3), pp. 111-122. ISSN: 2338-0950.
Williams, D.F. (1981) 'Extraction with Supercritical Gases', Chem. Engineering Sci, 36(11), pp. 1769-178 